\title{
CERTIFICATION PLAN \\ FOR REACTOR ANALYSIS COMPUTER CODES (U)
}

JANUARY 1990

WESTINGHOUSE SAVANNAH RIVER COMPANY SAVANNAH RIVER LABORATORY AIKEN, SC 29808

PREPARED FOR THE U. S. DEPARTMENT OF ENERGY UNDER CONTRACT DE.ACO9 88SR18035 
DISCLAIMER

This report was prepared by Westinghouse Savannah River Company (WSRC) for the United States Department of Energy under Contract DE-AC09. 88SR18035 and is an account of work performed under that Contract. Neither the United States, the United States Department of Energy nor WSRC, nor any of their employees, makes any warranty, express or implied, or assumes any legal liability or responsibility for the accuracy, completeness, or usefulness of any information, apparatus, product, or process disclosed herein, or represents that its use will not infringe privately owned rights. Reference herein to any specific commercial product, process or service by trade name, mark, manufacturer, or otherwise does not necessarily constitute or imply endorsement, recommendation, or favoring of same by WSRC or by the United States Government or any agency thereof. The views and opinions of authors expressed herein do not necessarily state or reflect those of the United States Government or any agency thereof. 
NRTSC

NUCLEAR REACTOR TECHNOLOGY AND SCIENTIFIC COMPUTATIONS

\title{
WS R C - T R - 90 - 26
}

KEY WORDS:

COMPUTER CODE REACTOR PHYSICS

THERMAL·HYDRAULICS

RETENTION PERIOD:

UNLIMITED

\section{CERTIFICATION PLAN \\ FOR REACTOR ANALYSIS COMPUTER CODES (U)}

\author{
By \\ H. Toffer \\ R. D. Crowe \\ K. N. Schwinkendorf \\ Westinghouse Hanford Company \\ R. E. Pevey \\ Scientific Computations Division \\ Savannah River Laboratory
}

ISSUED: JANUARY 1990

SRL SAVANNAH RIVER LABORATORY, AIKEN, SC 29808 Westinghouse Savannah River Company

Prepared for the U. S. Department of Energy under

Contract DE-AC09-88SR18035 


\section{PROJECT: Code Certification}

\section{DOCUMENT: WSRC-TR-90-26}

TITLE: Certification Plan for Reactor Analysis Computer Codes (U)

TASK: 
1.0 SUMMARY

2.0 INTRODUCTION

3.0 OBJECTIVES OF PLAN

4.0 BASIC ASSUMPTIONS

5.0 LIST OF CODES COVERED

6.0 QA REQUIREMENTS

7.0 CONFIGURATION CONTROL ACTION MATRIX

8. 0 GENERALIZED CONFIGURATION CONTROL PROCEDURE CHECKLIST

9.0 USER QUALIFICATIONS

10.0 RESOURCE REQUIREMENTS

11.0 TIME SCHEDULE

12.0 CONCLUSIONS

13.0 REFERENCES 


\subsection{SUMMARY}

A certification plan for reactor analysis computer codes used in Technical Specifications development and for other safety and production support calculations has been prepared. This plan fulfills the commitments by Westinghouse Savannah River Company (WSRC) to the Department of Energy Savannah River (DOE-SR) as identified in a letter to R.E. Tiller (Reference 1). Certification as described in Reference 1 covers verification and validation, computer code configuration control, and user qualification. The plan developed for verification and validation is contained in Reference 2 .

The certification plan is in compliance with the intent of the WSRC quality assurance requirements.

An action matrix, checklists, a time schedule, and a resource commitment table have been included in the plan. These items identify what is required to achieve certification of the codes, the time table that this will be accomplished on, and the resources needed to support such an effort.

A list of computer codes covered by the certification plan has been established. A description of each of the codes was provided in Reference 2. The action matrix for the configuration control identifies code specific requirements that need to be met to achieve the certification plan's objectives. The checklist covers the general procedures that need to be prepared in support of the configuration control effort.

A qualification checklist for users establishes the minimum prerequisites for achieving levels of proficiency in using configuration controlled codes for critical parameter calculations.

The development of the plan is based in part on the experience and insights of Westinghouse Hanford Company in their successful efforts to establish computer code compliance to quality assurance requirements. 


\subsection{INTRODUCTION}

As a consequence of Department of Energy (DOE) reviews of Savannah River Site (SRS) reactor operations, the DOE requested Westinghouse Savannah River Company (WSRC) in Reference 3 to demonstrate that the process employed to develop parameters used in Technical Specifications is valid. This requirement calls for a documented baseline of the computer codes essential to Technical Specification development. A certification plan has been developed to respond to this request. The plan addresses reactor physics and thermal hydraulics codes, but the plan's structure is sufficiently general to be applicable to computer codes in other disciplines. Subsequent revisions of this document could cover safety analysis as well as probabilistic risk assessment codes.

The software certification as defined in Reference 1 consists of three parts as shown in Figure 1. A plan for the verification and validation of existing computer codes was developed in Reference 2 . The remaining slices of the pie in Figure 1, the software configuration plan and user qualification plan are contained in this document. All three segments of the pie are of equal importance and need to be developed to an equivalent depth to assure the validity of calculated results. Critical values shall be computed by qualified engineers and scientists with verified and validated codes that are properly controlled.

The information flow when configuration controlled computer codes are applied by qualified users is illustrated in Figure 2 . There are essentially two main areas of interaction, the user community and the computer technology world. Both have distinct responsibilities pertaining to the control and use of certified software. In the user community, the cognizant user and the proprietor are the key individuals. Computer technology controls the machine related activities of code custodianship. The specific responsibilities of the various organizations are listed below the ovals in Figure 2 . The information flow is designated by arrows. The heavier arrows indicate the principal paths of information flow. There exists, on a reduced level, information exchange directly between the cognizant users and the code control custodian. 
Some of the codes covered by this plan were written as many as 20 years ago. At that time quality assurance requirements for software development, testing, and configuration control were neither defined in present day context nor did they contain current rigor. The documented configuration control record for most codes is incomplete. Despite these shortcomings in light of present day quality assurance requirements, the codes have been successfully used to predict the operating characteristics of the reactors, safety parameters, isotope production and certain key measurements for many years. The plan establishes the means and schedule to rectify the shortcomings to put in place documented certification of the codes.

The computer codes covered by this plan are those used directly in the computation of key Technical Specification parameters or employed to indirectly support Technical Specifications, charge design, or reactor operating limits.

The plan has been prepared in cooperation with Westinghouse Hanford Reactor Applications personnel acting as consultants to the SRS Reactor Physics organization. The Westinghouse Hanford Company has completed a similar activity within the last few years. Their experience, insights, and outside perspective have been essential and invaluable to the development of the plan.

The successful implementation of the certification plan requires an understanding of what is meant by code certification, configuration control and user qualification and the relationship of these terms to the SRS quality assurance documentation.

Certification as applied to existing software is the process for ensuring that software used in critical applications has been appropriately reviewed and documented for verification, validation, user qualifications and configuration control. Certified software complies with all applicable requirements identified in QAP IV-2, "Certification of Existing Software" (see reference 4). All software intended for use in critical applications must be certified.

Verification denotes the process which establishes that the theory is correct, has been properly coded and that the various code modules are functionally coupled to process information as required. 
Validation is the process that establishes how well a computer code can reproduce observed or measured reality such as experimental data obtained in special facilities, controlled experiments in operating facilities, operational data or benchmarks. Benchmarking refers to the process of evaluating the performance of one computer code relative to another code or to an exact solution.

Configuration Control is a system to manage and control computer software to provide a certified version of a code for the qualified user. Configuration control prevents unauthorized changes or use of the software coding and establishes a method of handling discrepancies including correction of errors. It also governs retention of supporting documentation such as certification records, user documentation, installation instructions, and benchmark testing results.

User Qualification identifies the minimum levels of proficiency and authorization required for individuals to use certified software for critical application computations.

\subsection{OBJECTIVE OF PLAN}

The objective of the Certification Plan is to establish a documented certification process for the defined set of computer codes and their application to Technical Specification calculations as spelled out in the letter to R.E. Tiller, August 11, 1989 (Reference 1).

The parts constituting certification in Reference 1 include:

o Verification and Validation (see Reference 2)

- Software Configuration Control

- User Qualification

\subsection{BASIC ASSUMPTIONS}

In the past, computer codes were developed and operated outside the rigorous framework of the present day quality assurance requirements (Reference 3). Nevertheless, these codes, utilized by 
knowledgeable individuals, were successfully applied to computing key parameters for safe operation of the reactors. It is anticipated that in some instances past practices can be fitted into the present day requirements. In other instances, new certified practices will have to be established and implemented. Some level of configuration control has been present in past practices. User Qualification was implicit in the job requirements of engineers and scientists performing the analyses.

\subsection{LIST OF CODES COVERED}

A list of pertinent reactor physics, thermal hydraulics, and safety analysis codes has been assembled. The codes covered are:
A A 3
FLOWTRAN-TF
GILDA
GRIMHX
ICG
LLAP
PIPEFLOW
PORAD
SCALEUP
TRAC/MOD1
WIGGLE

FLOWTRAN-FI

FLOWZONE

GLASS

HMTABLE

JASON

MARCO

PLENUM

RELAP5

SHIELD

TRIMHX

Code descriptions for the above listed codes are contained in Reference 2 .

\subsection{QA REQUIREMENTS}

It is the intent of this Certification Plan to parallel the QA requirements for code certification of existing software as described in Reference 4, in particular Section IV-2, "Certification of Existing Software." References in this Certification Plan to software alterations must comply with Section IV-5, "Software Change Control" (Reference 4). Software Configuration Control requires several activities, as discussed throughout Section IV of Reference 4. Included in these are Sections IV-7 and IV-9 ("Software Testing" and "Benchmark Testing", respectively), which would follow code alterations, and particularly Section IV-8, "Software Configuration 
Control." Thus the work performed for this plan is directly applicable to tasks required for Code Certification under the present QAP manual.

\subsection{ACTION MATRIX CONFIGURATION CONTROL}

An action matrix for achieving configuration control has been developed and is shown in the Figure 3. The matrix identifies the different types of activities that need to be completed. The matrix serves as a useful tracking mechanism for monitoring the completion of tasks. In the matrix, the names of the various codes are listed, as well as a series of action items required under configuration control. The activities are grouped by topics. The first group covers activities in the user community. The topics in the second group pertain to activities in the computer technology world and user community. The last category deals with the completion process for configuration control.

Not all the boxes are relevant for each computer code. For example, special shell scripts may be required for only a few codes while others would use a standard script. Consequently, there are two ways for each box to be completed and checked off, either by performing the special tasks identified for each box or referencing a general situation that is applicable for the particular code. In either case, this information is to be included in the documentation for the particular box.

The following sections give a detailed description of what is required for the specific action items.

\subsection{Code Proprietors}

Has a code proprietor been identified for a specific code?

A technically knowledgeable person should be assigned to each computer code. This individual would be a member of the user community. He would be an experienced individual very familiar with the specific computer code. He must be able to provide the functions explained under the proprietor responsibilities, as well as meet the qualifications described in the user qualification sections. Considerations should be given for identifying a backup proprietor to 
ensure continuity of code expertise.

\subsection{Proprietor's Code Log Book}

Has a proprietor's code log book been established for each computer code?

The proprietor for each specific computer code should have a notebook dedicated to each specific code in which an ongoing history of code development, alterations, and error corrections is maintained. Such a notebook would focus on the technical aspects of the code rather than the response of the code to system or computer configuration changes. The latter responses are recorded as a part of 7.8, Controlled Tracking System.

\subsection{Cognizant User Qualifications}

Are user qualifications in place for using a specific controlled code?

Only cognizant users should use the controlled codes for critical parameter computations. The general qualification requirements for users are covered in Section 9.0, User Qualifications.

\subsection{User Manual Availability}

Where is the User Manual located and how would a user obtain updated instructions?

User Manual preparation is required as a part of the Verification and Validation Plan. It is important for the user to know where to obtain the current updated User Manual. This implies that the code user should be assured that the central document repository has an updated User Manual. If this is not the case then the user needs to be informed where the most recent changes are documented and where assistance in their interpretation can be obtained. A Code Proprietor could have more recent information than contained in the latest User Manual. Sources other than manuals such as special video tapes or computerized tutorials supplementing User Manuals need to be identified. 


\subsection{Training Package}

Is a training package in place for using a specific code?

The complexity of the code will dictate the amount of training needed for the use of a specific code. The training package could consist of menu driven familiarization programs, a section in the User Manual with special sample problems, presentations by trainers, special video tapes, or special courses. For each code, the required materials need to be identified, assembled, and supplied to the training function.

\subsection{Code Source Listing Locations}

Has the location of controlled code listing been identified?

The users and proprietor should have access to code listings either as a hardcopy or as a protected computer file that cannot be readily modified. Therefore the location of such information should be identified for each of the codes.

\subsection{Test Problem and Results}

Has the location of test problems and test results been identified?

A set of test problems for each of the codes will be developed under the Verification and Validation Plan. The user community should be aware of where to find an updated set of test problems and also the testing records for each of the codes for current and archived versions.

\subsection{Controlled Tracking System}

Has a controlled tracking system been established for each of the codes?

An electronic or hard copy system should be in place for each code such that a record of the coding changes, observed impact of system changes, and error corrections are available to the user community. 


\subsection{System Dependent Code Documentation}

Is the system dependent code documentation in place?

Computer codes vary in complexity. They may also be processed on different machines and with different operating systems.

Documentation needs to be in place that informs the user of what machines the code can be processed on, where the required databases are, and what are the specific controls required to access them. Information not included in the User Manual would be included in separate documentation.

\subsection{Code Interactions}

Have the code interaction impacts been identified?

Some of the computer codes are interrelated. Changes made to one code can impact the results of another code. Documentation should be in place for each code identifying if it is part of an interrelated code system; if so, the relationships and interactions should be described. The potential impact on the system of codes of changing an individual code should be identified. Some of this information would be included in the User Manual.

\subsection{Range of Applicability}

Has the range of applicability for critical parameter computations of a particular code been identified?

Each code is used for identified specific purposes. The Verification and Validation process established assurance that the code will compute critical parameters within known limits. Alterations to a code, to the system or other configuration changes could modify the established range of applicability of a code. Therefore, this range should be carefully spelled out for the controlled version of the code and reevaluated upon subsequent alterations. This information will be contained in the Verification and Validation Documentation.

\subsection{Backup Versions}

Are backup versions of the code in place? 
It is anticipated due to the multiplicity of machines in use that the same version of a code will reside on different machines and thereby provide backup. The same code version may also reside at alternate sites as part of disaster recovery arrangements.

Documentation needs to be in place identifying where the codes reside, where backup versions are located and how upgrading and code maintenance can be performed uniformly and consistently for all code locations.

\subsection{Shell Scripts and Banners}

Have shell scripts and banners been developed for the codes?

Shell scripts and banners or page headings are very useful identifiers for assuring that computations are being performed with controlled versions of the code and for documenting the specific dates of the computation. Shell scripts can also provide users with pertinent control and operation information. It is conceivable that details of shell scripts could contain code specific information or controls. Code specific information pertaining to individual shell scripts should be documented in the User Manual.

\subsection{Configuration Review}

Has a code configuration control review been completed?

Every code should be passed through a technical review to establish if configuration control is in place and to declare that the code is ready for critical computations. A technical review group will be established composed of SRS Computer Technology and user community personnel with support from consultants. The review will be conducted in accordance with accepted QA requirements. A report generated by this group would recommend acceptance of configuration control for a particular code.

\subsection{Configuration Control in Place}

\section{Is computer code configuration control in place?}

Following the technical review group recommendation, configuration control of a particular code is accepted by the management of the 
specific user and Computer Technology organizations. A report by the appropriate managers will satisfy the Department of Energy Savannah River Office of the completion of this activity.

\subsection{GENERALIZED CONFIGURATION CONTROL PROCEDURE CHECKLIST}

In addition to the code specific action matrix, a series of generalized procedures need to be implemented to govern the configuration control process. The suggested generalized procedures with an explanation of their scope are described below. The completion of a draft of the procedure and the implementation of the approved procedure would be tracked.

\subsection{Moving A Code Into Configuration Control}

After a computer code has gone through the development stage, a verified and validated version should be submitted for placement under configuration control. This procedure covers the process and what constitutes configuration control.

\subsection{Operating under Configuration Control}

This procedure covers the process of how a user would use a computer code that is under configuration control for a critical calculation.

\subsection{Changes that Proprietors Make}

This procedure covers the steps necessary to implement changes made by the proprietor to a certified code.

\subsection{Changes in Computer Environment}

This procedure covers the steps that need to be taken with respect to controlled codes when changes in the computing environment are made.

\subsection{Archiving Responsibilities and Backup Disaster Control}

This procedure covers the archiving of controlled software and test problems associated with testing the codes. The scope should address how multiple versions of the code are archived and how disaster control 
backup versions are maintained.

\subsection{Retired Codes}

The procedure addresses how and when to retire a code; what records to keep on retired codes and how to retrieve the information in the future.

\subsection{Tracking of Configuration Control Documentation}

This procedure covers what documentation on controlled codes should be tracked, how it is to be tracked, and what documentation needs to be generated.

\subsection{Error Identification and Correction Procedures}

This procedure describes how an error discovered by a user is implemented as a correction in the controlled code. The procedure should cover verification testing.

\subsection{Generalized Training Requirements for Users and Operators}

This procedure addresses generalized training for users and operators in the operation and maintenance of configuration controlled codes.

\subsection{Periodic Code Testing With Test Problems}

This procedure establishes periodic testing requirements for controlled codes.

\subsection{Use of Work Stations and PCs in Critical Calculations}

A procedure will cover the handling of configuration control for work stations and personal computers should such devices be used to compute critical parameters.

\subsection{USER QUALIFICATIONS}

\subsection{User Level Description}

As a part of the third segment of the certification plan, user qualification requirements are considered. 


\section{CERTIFICATION PLAN FOR REACTOR ANALYSIS COMPUTER CODES

Within the user community, there are three levels of proficiency relative to the use of configuration controlled computer codes for critical calculations: Apprentice User; Cognizant User; and Code Proprietor. The designation of an individual as an Apprentice or Cognizant User is the joint responsibility of the task leader and appropriate management.

\subsubsection{The Apprentice User}

The Apprentice User is a person who is in training to use the code and would work under the tutelage of a cognizant user or proprietor. This individual generally is in the process of learning to understand the purpose of the code calculations, to follow the input logic and selection of certain variables, and pick out specific results from the output.

The Apprentice User may have a significant understanding of the physical processes being evaluated by the code, but individual code systems may have their own input peculiarities which require specific code familiarity to avoid incorrect results. The Apprentice User may perform independent non critical analyses, but input and output should still be checked by a more experienced Cognizant User. The Apprentice User does not perform critical parameter analyses.

\subsubsection{The Cognizant User}

The Cognizant User is someone with experience in executing the computer code. He has been designated by management as a Cognizant User. As such, he understands the purpose of the code and is familiar with the code's input requirements and output. A Cognizant User is aware of the quality assurance requirements for documenting computer calculations required for critical applications and is qualified to perform such analyses.

The Cognizant User is sufficiently familiar with the code input and output to perform independent analyses, but may not possess sufficient understanding of the software coding to make changes to the code. He should be familiar enough with the code to identify when it is not functioning properly. He notifies the code proprietor of any possible error conditions and requests the proprietor to make 
any necessary changes.

\subsubsection{The Code Proprietor}

The Code Proprietor has an in-depth understanding of the software's coding structure and how the code works. He as been designated by management as a code proprietor. Each computer code has its own Proprietor. The Proprietor shall understand the logical flow of the code and the numerical methods used by the code, both with respect to theory and range of applicability. $\mathrm{He}$ is sufficiently familiar with the code to make coding changes, verify the programming, and validate the code against example problems. The Proprietor is aware of the quality assurance requirements for configuration control, verification, and validation. The Proprietor maintains a notebook in which code evolution is tracked. Changes to the code and the impact of these changes are recorded. This individual maintains a record of validations and performs necessary validations following changes to the code. The Proprietor is considered to be a Cognizant User. There should be only one Code Proprietor for each computer code with a trained backup person identified.

\subsection{Minimum Requirements for User Levels}

There are certain minimum standards which are required for an engineer or scientist to reliably perform computer code calculations in a technical field. These minimum requirements will help to ensure that the person has an adequate technical background for the various levels of user qualification. The User Qualification And Function Checklist contains guidelines for what a code user would have to attain to become qualified for the various levels.

\subsection{User Qualification And Function Checklist}

Some of the requirements listed in the User Qualification And Function Checklist should be considered as guidelines, and not as absolutes. For example, a highly competent engineer who is capable of learning new concepts at a faster pace than most others should not be limited to a full year of work experience before being allowed to work independently, especially if he has a significant academic background in the field he is currently working in. Decisions of this nature should be left up to the discretion of their immediate management. Designation of individuals to the various user levels 
should be documented by management.

\subsection{Additional Training}

In order to instruct people in the use of a particular code, it may be beneficial to provide special training seminars on the computer code's numerical methods and practical use. Course material for such a seminar would include numerous sample inputs for a variety of problems normally solved by the code, and would cover many of the different capabilities of the code system.

Such training seminars (when available) would be invaluable to Apprentice Users, in giving them a "steeper" learning curve, and could also help Cognizant Users gain an improved understanding. These training seminars and workshops, could be taught by the Code Proprietor or other experts.

\section{USER QUALIFICATION AND FUNCTION CHECKLIST}

\section{Aporentice Cognizant Proprietor}

Formal Education in

Relevant Discipline

$\begin{array}{lll}X & X & X \\ X & X & X\end{array}$

Completed Code Training

Familiar with Technical Area of Computation

X $\mathrm{X}$ X

Familiar with QA Requirements

$\begin{array}{lll}\text { X } & \text { X }\end{array}$

Minimum Experience (Years)

$\mathrm{X} \quad \mathrm{X}$

Performs And Reviews Critical Calculations

Performs Required

Code Alterations 
These requirements should be considered as guidelines, but progression of users to higher levels of responsibility requires documented management concurrence.

\subsection{RESOURCE REQUIREMENTS}

The estimated manpower required to complete the configuration control and certification efforts are given below:

\section{Configuration Control Effort}

\begin{tabular}{|c|c|c|c|c|}
\hline Physics & 8 & $\begin{array}{l}\text { FY } 1990 \\
\text { man-months }\end{array}$ & 6 & $\begin{array}{c}\text { FY } 1991 \\
\text { man-months }\end{array}$ \\
\hline $\begin{array}{l}\text { Thermal. } \\
\text { hydraulics }\end{array}$ & 4 & man-months & 3 & man-months \\
\hline $\begin{array}{l}\text { Computer } \\
\text { Technology }\end{array}$ & 12 & man-months & 9 & man-months \\
\hline OTAL & 24 & man-months & 18 & \\
\hline
\end{tabular}

\section{User Certification Effort}

$\begin{array}{llll}\text { Physics } & 6 & \begin{array}{l}\text { FY } 1990 \\ \text { man-months }\end{array} & \text { FY } 1991 \\ \begin{array}{l}\text { Thermal. } \\ \text { hydraulics }\end{array} & 2 & \text { man-months }\end{array}$

\subsection{TIME SCHEDULE}

The time schedule for completion of the certification process for the Physics and Thermal Hydraulic codes requires that the verification and validation be in place, the codes are under configuration control 


\section{CERTIFICATION PLAN FOR REACTOR ANALYSIS COMPUTER}

CODES (U)

and the users of the codes have been qualified. Individual milestones for configuration control and user qualification are listed in Table 1.

\subsection{CONCLUSIONS}

A Plan has been established that brings certain computer codes essential to Technical Specifications development and other codes needed for safety analysis and production predictions into compliance with certification requirements. This plan is sufficiently general that it can be applied to other existing computer codes in the area of reactor and criticality safety. 
1. Letter, "Technical Specification Parameter Justification", P.W. Dickson to R.E. Tiller, August 11, 1989.

2. H. Toffer, et al., Validation and Verification Plan for Reactor Analysis Computer Codes, WSRC-RP-89-1249, 1989.

3. Letter, "Approval of Technical Specification", P.W. Kasper to J. S. Moore, May 26, 1989.

4. A.A. Zagrodnik, QA Procedures for the Nuclear Reactor Technology and Scientific Computations Program Management Team, DPSTM-88-700-9, 1988 


\section{Figure 1. Software Certification for Critical Applications}

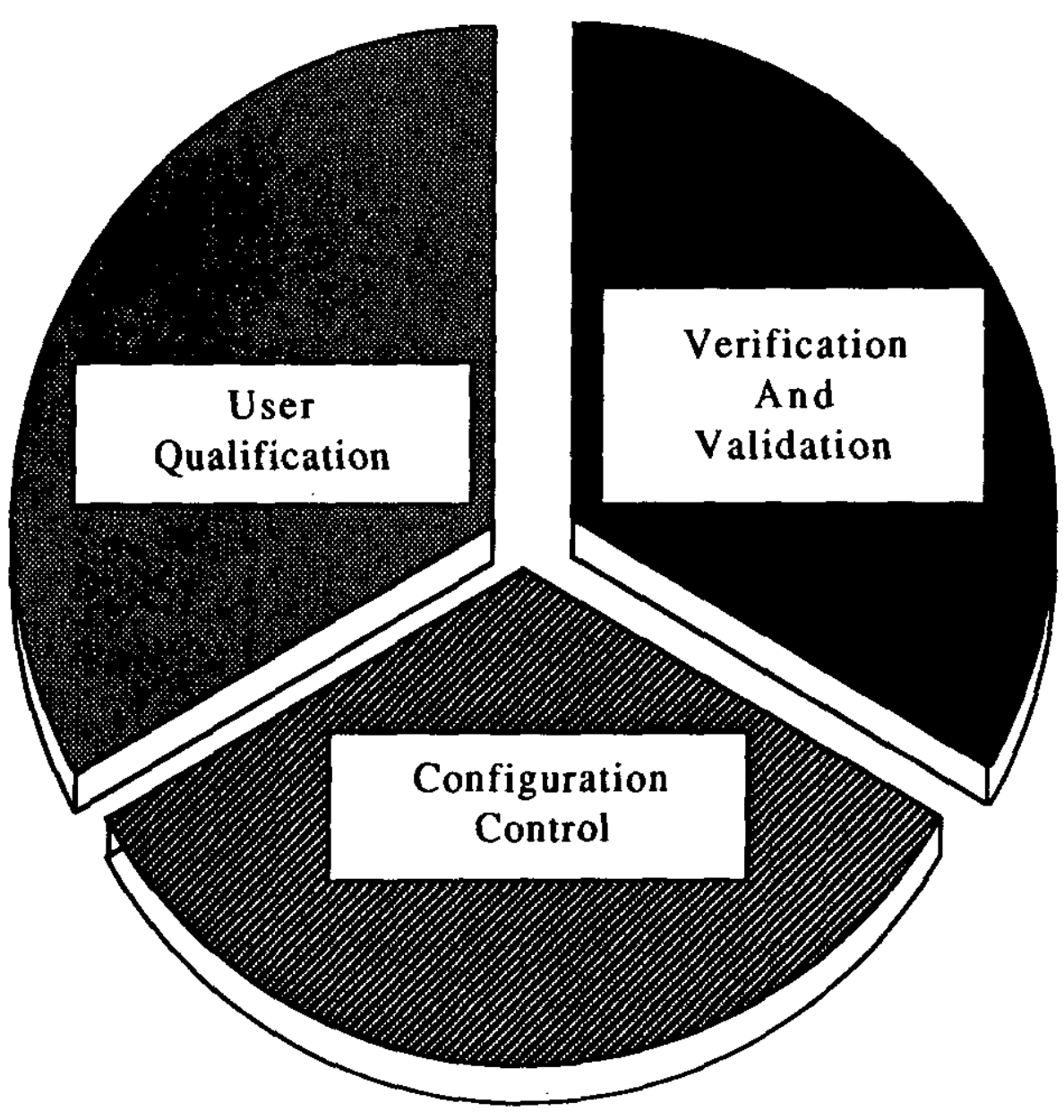




\section{Figure 2 Certification Plan Information Flow}

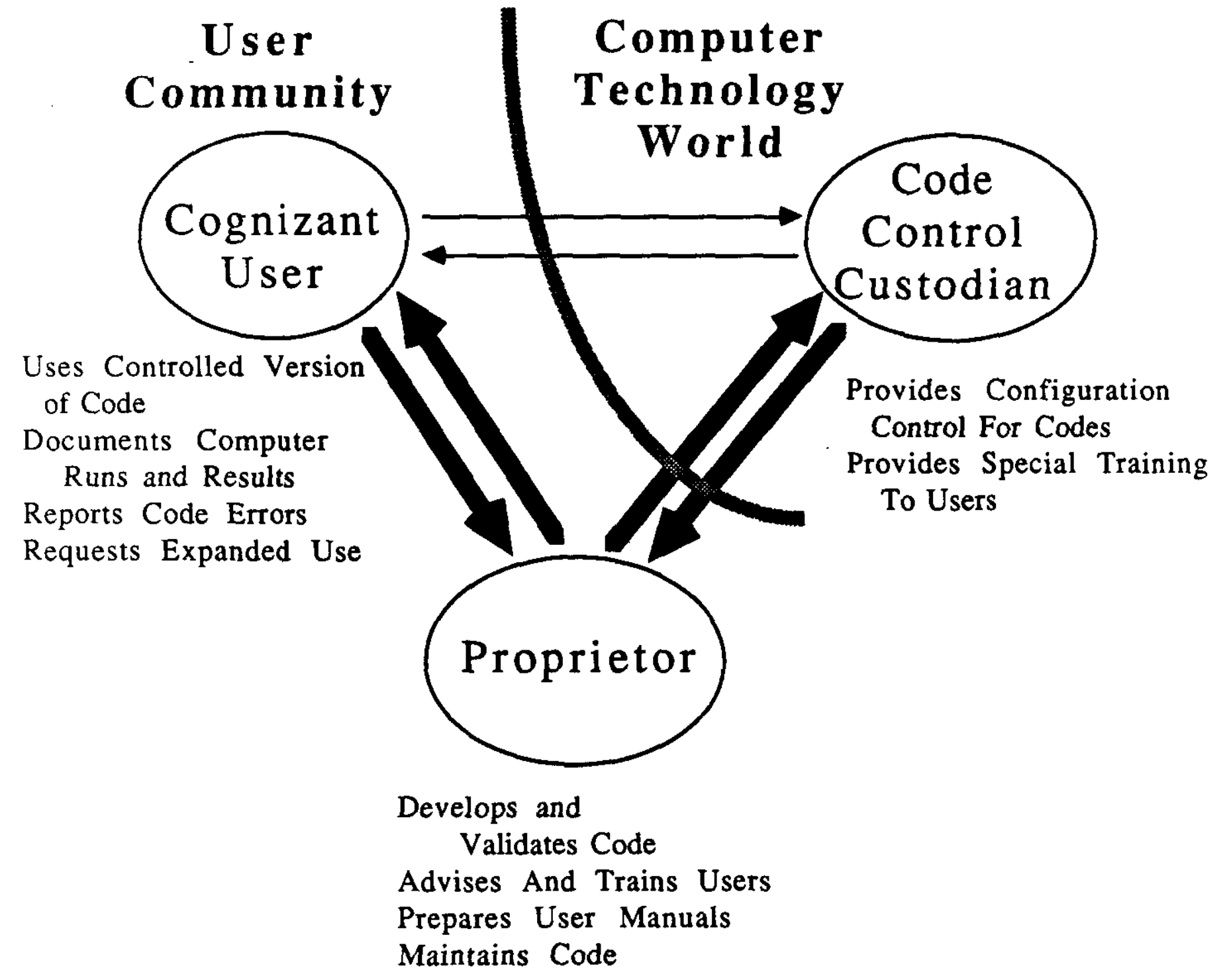




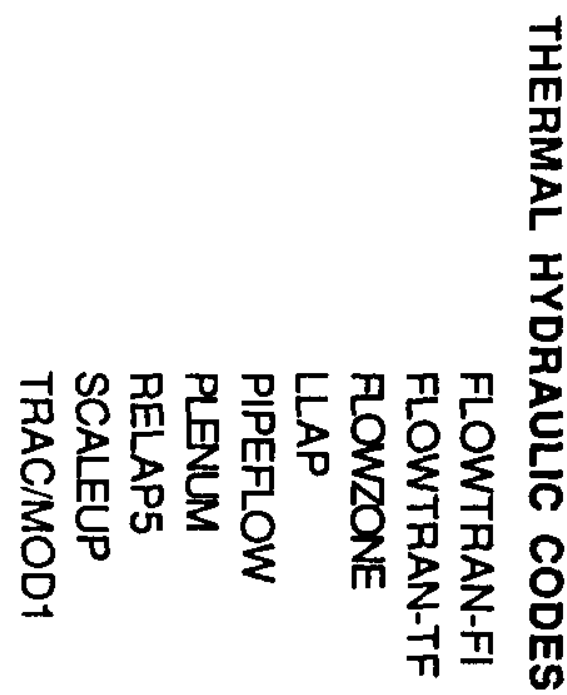

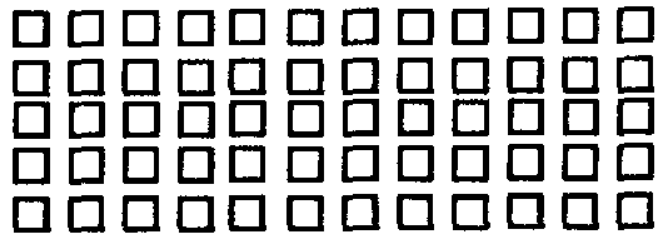

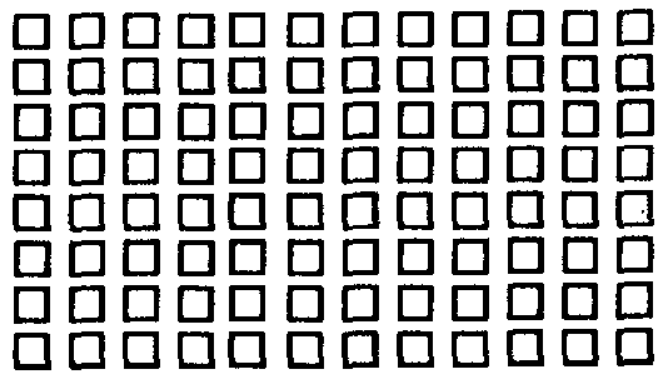

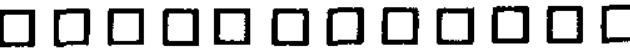
맘ำ

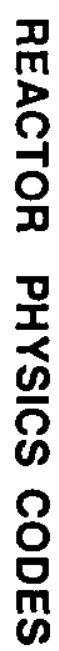

Code Proprietors

Proprietor's Code Log Book

Cognizant User Qualifications

User Manual Availability

Training Package

Code Source Listing Location

Test Problem And Results Location

Controlled Tracking System

System Dependent Code Documentation

Code Interaction Impact

Range of Applicability

Back Up Versions

Shell Scripts and Banners

Configuration Control Review

Configuration Control In Place 


\section{Table 1. \\ Configuration Control and User Qualification Activity Milestones}

\section{Milestones}

A. Matrix Responsibilities Defined and Code Proprietors Established

February 13, 1990

B. Code Proprietor Logbooks Established

July 3,1990

C. User Qualification System In Place

July 31,1990

D. Draft of the Configuration Control Procedures Completed

August 28, 1990

E. User Manuals in Place

September 30,1990

F. User Qualification Completed

September 30,1990

G. Generalized Configuration Control

Procedures In Place

October 30,1990

H. Training Packages For Codes Established

October 30, 1990

I. Configuration Control Action Matrix Completed

January 29, 1991

K. Configuration Control Review Comments Resolved

August 20, 1991 


\section{DISTRIBUTION}

J. R. Patterson, DOE, 703-41A

R. D. Rollins, DOE, 703-41A

R. K. Franks, DOE, 703-41A

T. M. Tran, 703-41A

J. L. Gallagher, 703-A

R. T. Begley, 773-A
A. F. McFarlane, 703-A
G. H. Clare, 703-A
C. L. Peckinpaugh, 704-C
F. Beranek, 704-C
D. B. Rankin, 704-C
J. D. Spencer, 773-A
D. C. Richardson, 773-A
M. J. Hitchler, 773-A
D. J. Baker, 773-41A
M. R. Buckner, 773-A
C. E. Apperson, 773-59A
R. E. Pevey, 773-59A
P. L. Ames, 773-42A
A. J. Garrett, 773-41A
RRP Chron File, 703-A

DM, 703-A, E-142 (File 89071906) 